\title{
Power and agility testing within the NBA pre- draft combine
}

\section{Teste de potência e agilidade no NBA pre-draft combine}

\author{
Fabrício J. Milan \\ (D) https://orcid.org/0000-0003-1724-3722 \\ André L. A. Soares \\ (D) https://orcid.org/0000-0001-6629-656X \\ Ricardo T. Quinaud \\ (D) https://orcid.org/0000-0001-6043-3658 \\ Luisa D. Kós \\ (D) https://orcid.org/0000-0002-2280-6262 \\ Carlos E. Palheta \\ (D) https://orcid.org/0000-0001-7066-7562 \\ Felipe G. Mendes \\ (D) https://orcid.org/0000-0001-9552-754X \\ Juarez V. Nascimento \\ (D) https://orcid.org/0000-0003-0989-949X \\ Humberto M. Carvalho \\ (D) http://orcid.org/0000-0002-2855-0296
}

Abstract - Considering agility is a prerequisite for basketball performance and several agility tests have been used during the pre-draft assessment of the National Basketball Association (NBA), the aimed of this study was to examine the associations between pre-draft athletes' performance scores in NBA draft combine testing protocol. The performance of 480 athletes invited to the NBA pre-draft assessment from 2010 to 2017 was considered. Tests in the NBA Draft Combine considered in this study included the Shuttle Run Test, Lane Agility Test, Sprint Test, and Jump Test (standing vertical leap). Zero order correlations were calculated to examine the associations between performance tests by fitting Bayesian linear regression models. Among running testing, both Shuttle Run Test $[\mathrm{r}=0.45,95 \%$ confidence interval (CI) 0.34 to 0.56$)$ and Sprint Test ( $r=0.45,95 \%$ CI 0.37 to 0.54$)$ were moderately associated with the Lane Agility Test. The association between the Sprint Test and Shuttle Run Test was moderate at best ( $\mathrm{r}=0.27,95 \% \mathrm{CI} 0.16$ to 0.38$)$. Correlations between Jump Test and running tests were moderate to large, ranging from -0.51 to -0.19 (Lane Agility Test: $r=-0.33,95 \%$ CI -0.42 to -0.24 ; Shuttle Run Test: $r=-0.19,95 \%$ CI -0.31 to -0.07 ; Sprint Test: $r=-0.51$, $95 \% \mathrm{CI}-0.59$ to -0.43$)$. As a conclusion, we found a moderate to large correlations between the tests performance of the NBA Draft Combine, implying that the overall procedures may provide in part overlapping information about basketball maximal short term performance.

Key words: Agility; Athletic performance; Basketball; Power.

Resumo - O objetivo deste estudo foi examinar as associaçôes entre os escores de desempenho dos atletas no Pre-Draft Combine da NBA. Foram examinados os desempenhos de 480 atletas nas avaliaçôes do Pre-draft Combine da NBA de 2010 a 2017. Os testes do Draft Combine considerados incluiramo Shuttle Run Test, o Lane Agility Test, o Sprint Test e o Jump Test (salto vertical em pé). Correlações de ordem zero foram calculadas para examinar as associaçôes entre os testes de desempenho através da adequação de modelos de regressão linear Bayesiana. Entre os testes de corrida, tanto o teste Shuttle Run $(r=0,45$, intervalo de confiança (IC) de 95\% 0,34 a 0,56) e teste de Sprint $(r=0,45$, IC 95\% 0,37 a 0,54) foram moderadamente associados com o Teste Lane Agility. A associação entre o Sprint Test e o Shuttle Run Test foi de moderada para alta $(r=0,27, I C 95 \%$ 0,16 a 0,38). As correlaçóes entre o Teste de Salto e os testes de corrida foram de moderada a grande, variando de -0,51 a -0,19 (Lane Agility Test: $r=-0,33, I C$ 95\%-0,42 a-0,24; Teste Shuttle Run: $r=-0,19$, IC 95\%-0,31 a -0,07; Teste de Sprint: $r=-0,51, I C 95 \%-0,59$ a -0,43). Assim, foi verificado uma correlação de moderada a grande entre o desempenho dos testes do Draft Combine da NBA, o que indica que os procedimentos gerais podem fornecer, parcialmente, informaçôes sobrepostas sobre o desempenho máximo de curto prazo do basquetebol.

Palavras-chave: Agilidade; Basquetebol; Desempenho atlético; Potência.
1 Universidade Federal de Santa Catarina. Florianópolis, SC. Brasil

Received: 20 October 2018 Accepted: 30 May 2019

How to cite this article Milan FJ, Soares ALA, Quinaud RT, Kós LD, Palheta CE, Mendes FG, Nascimento JV, Carvalho HM. Power and agility testing within the NBA pre-draft combine. Rev Bras Cineantropom Desempenho Hum 2019, 21:e59838. D0l: http://dx.doi. org/10.1590/1980-0037.2019v21e59838.

Copyright: This work is licensed under a Creative Commons Attribution 4.0 International License. 


\section{INTRODUCTION}

The National Basketball Association (NBA) is considered the most competitive basketball league in the world. To maintain its quality, the decision to choose a player depends on several factors, such as individual statistics, physical tests, and technical skills ${ }^{1}$. Thus, the NBA Draft Combine consists of a test protocol that includes anthropometry, athletic skills and shooting skills, as well as scrimmages (Standing Reach, Wingspan, Standing Vertical Leap, Max Vertical Leap, Shuttle Run, Lane Agility, Three Quarter Sprint, NBA Break Left Shooting percentage, NBA Break Right Shooting percentage, NBA Corner Left Shooting percentage, NBA Corner Right Shooting percentage). The protocol was developed by the National Basketball Conditioning Coaches Association (NBCCA) testing committee, attempting a valid, reliable, and directly related to the performance and physical qualities of basketball testing battery, besides being easily replicated ${ }^{2,3}$.

Among these several measurements, agility and the power measures appear to be mostly valued, being been using the test battery for the predraft combine since 2010 (https://stats.nba.com/draft/combine/) and often considered a prerequisite for basketball performance given the multiple changes of direction within game actions ${ }^{4}$. These measurements were developed in order to help NBA teams evaluate prospective players in a more efficient manner and studies have identified that the NBA Draft Combine has some predictive validity for player's future performance and that the Combine data could be used to supplement the evaluation of prospective players ${ }^{2,5}$. Although, it has been identified that the most individual pre-draft combine measures per se are not highly associated with future on-court performance ${ }^{2}$.

On the other hand, in studies with the NFL Combines, there were not found the usefulness of it for predicting the player's performance ${ }^{6}$, ${ }^{7}$ and they suggest the elimination of those test that are useless and the inclusion of only tests that actually predict success at the professional level. Thus, considering the necessity to identify the tests efficacy and to prevent the testing procedures overlap, the aim of this study was to examine the associations between pre-draft athletes' performance scores in NBA draft combine testing protocol.

\section{METHODS}

\section{Study design and data}

This study is based on the measurements of basketball players participating in the NBA Draft Combine between 2010 and 2017. The data is freely available at the official NBA's Draft Combine website (https://stats.nba. $\mathrm{com} / \mathrm{draft} / \mathrm{combine} /)$. Hence we considered the performance of 480 players, aged between 17.8 to 28.0 years $(21.5 \pm 1.46$ years). 


\section{Procedures}

The NBA's Draft Combine testing battery is composed by: (i) lane agility drill, which is based on a regular three second area within the NBA court, the athlete sprints forward for $5.8 \mathrm{~m}$, then proceed with defensive shuffle movement across the free-throw line, followed by a backpedaling until the baseline $(5.8 \mathrm{~m})$ and defensive shuffle to the starting point. To complete the test, the players completed by the inverse path; (ii) shuttle run, this is a test of speed, body control and the ability to change direction (agility), as well as reaction time that uses the marking of the standard NBA basketball court $(9,76 \mathrm{~m})$. The player starts by straddling the middle line. When indicated by the measuring system, the player runs either to the right or left direction, and places his foot on or over the sideline of the key. He then runs 16 yards back to the opposite line, then finally turns and finishes by running back through the start/finish line. The score is the best time of three trials; (iii) sprint test, the aim of this test is to determine running speed over $3 / 4$ court distance (75 feet, 22.86 meters), using marked basketball court with 4 cones, the athlete performs a maximum sprint in 3/4 of a basketball from the baseline until the final line marking; (iv) jump tests (standing vertical leap), is a countermovement jump executed from a stationary position with arm swing to propel the body upwards generating additional propulsion. The athlete stands away from the instrument and leaps vertically as high as possible using both arms and legs to assist in projecting the body upwards.

\section{Statistical analysis}

Descriptive statistics for each test performance were calculated. Initially, we visually explored the data distribution trends. Then we examined associations, zero-order correlations, between performance tests by fitting bayesian linear regression models. We used uninformative informative prior distributions, allowing model convergence, as well as ensuring that results reflect the knowledge available on the current data. We then run four chains for 4,000 iterations with a warm-up length of 2,000 iterations. The models were implemented with bayesian methods via Markov Chain Monte Carlo (MCMC) simulation and using Hamiltonian Monte Carlo and its extension, the No-U-Turn Sampler using $\operatorname{Stan}^{8}$, obtained using "rethinking" package ${ }^{9,10}$, available as a package in the $\mathrm{R}$ statistical language ${ }^{11}$.

\section{RESULTS}

The correlation between pre-draft athletes performance scores in NBA draft combine testing protocol are summarized in table 1 .

Correlation between two used jump tests was very large, thus we considered the score of the standing vertical leap to describe jump performance in the analysis. Among running testing, the correlations of Lane Agility Test with the other running tests were moderate to large. The correlations of jump performance with Lane Agility Test and Shuttle Run were was small, but moderate to large with Sprint test. 
Table 1. Correlation between tests.

\begin{tabular}{lrrr}
\hline & Lane Agility Test & \multicolumn{1}{c}{ Shuttle Run } & \multicolumn{1}{c}{ Sprint } \\
\hline Lane Agility Test & & & \\
Shuttle Run & $.45(.34$ to .56$)$ & & \\
Sprint & $.45(.37$ to .54$)$ & $.27(.16$ to .38$)$ & \\
Jump & $-.33(-.42$ to -.24$)$ & $-.19(-.31$ to -.07$)$ & $-.51(-.59$ to -.43$)$ \\
\hline
\end{tabular}

\section{DISCUSSION}

In this study, we examined the associations between pre-recruitment athlete performance scores in the NBA combined test protocol. Candidate pre-draft players represent a highly selected group of expert players in basketball. Hence, between player variation is very narrow. Considering the associations between the performance scores of pre-draft athletes in the NBA combination test protocols, the present data showed a moderate to large correlation between running test performances, suggesting that the tests may measure, at least in part, similar performance properties of agility and power. Sprint, change of direction, and muscle power in the lower body are likely to be determinants of performance in all test procedures. However, a substantial part of the variability remains unexplained, revealing the need to explore the validity of the tests applied in the NBA draft combine ${ }^{4}$.

It has been noted previously that the predictive validity of the Draft is likely to be exaggerated ${ }^{12,13}$. For example, physical attributes and speed did not appear to be sensitive to distinguishing among players from the NBA ${ }^{14}$. On the other hand, it seems to be apparent that the speed and superior body strength do not present relevance to predict the order of the Draft ${ }^{2}$, in contrast to perceived relevance of athletic skills to basketball performance ${ }^{15}$. It appears likely that body dimensions ${ }^{16}$ and scrimmage individual data data $^{12}$ may be more valued than physical testing when selecting players in the draft as physical measurements in the Combine scores do not appear to be associated with future performance on the court (as measured by players game statistics) ${ }^{2}$. This may be explained by either, players performance homogeneity in the pre-draft combine physical measurements, and limited validity of the measurements to discriminate players.

Despite similar basketball specific movements (sprint, defensive shuffle, and jump), the NBA pre-draft combine tests likely maintain independent characteristics that may add valuable interpretations when selecting players. However further inspections are required to examine the validity of the procedures to predict future NBA career.

NBA Draft Combine may represent an important element for the player selection, the substantial overlap between running performance test (agility) suggests that a more economical testing procedure may be done, likely attaining a similar rank order between players' order. This suggestion can provide a wisely money spending and a more qualified NBA Draft Combine.

There were several players in the NBA combine that did not complete part or all the testing procedures, and in some cases plyers drafted with 
the highest selections. Other limitation is the lack of information about the measurements reliability. Considering the missing description and reliability estimates for body dimensions, we did not partition the influence of body size on the physical tests.

\section{CONCLUSION}

The present study showed a moderate to large correlation between the the agility and power testing procedures of the NBA pre-Draft Combine. Hence, the overall procedures may provide an overlapping information about basketball maximal short-term performance and it would be likely useful to review the need to perform the full testing procedures. Given the association between the measures in the combine, future research should explore the procedures validity in relation to the athletes' career in the NBA.

\section{COMPLIANCE WITH ETHICAL STANDARDS}

\section{Funding}

This study was partially supported by the Federação Catarinense de Basketball (FCB). The first author was supported by the Conselho Nacional de Desenvolvimento Científico e Tecnológico (CNPq); the second and third authors were supported by the Coordenação de Aperfeiçoamento de Pessoal de Nível Superior (CAPES).

\section{Ethical approval}

This research is in accordance with the standards set by the Declaration of Helsinki.

\section{Conflict of interest statement}

The authors have no conflict of interests to declare.

\section{Author Contributions}

Conceived and designed the experiments: HMC, FJM, FGM. Performed the experiments: ALAS, HMC. Analyzed the data: FJM, HMC, RTQ, ALAS. Contributed reagents/materials/analysis tools: LDK, CEP, RTQ. Wrote the paper: FJM, FGM, RTQ JVN, HMC.

\section{REFERENCES}

1. Sullivan C, Kempton T, Ward P, Coutts AJ. Factors associated with early career progression in professional Australian Football players. J Sport Sci 2018;36(19):2196-201.

2. Teramoto M, Cross CL, Rieger RH, Maak TG, Willick SE. Predictive Validity of National Basketball Association Draft Combine on Future Performance. J Strength Cond Res 2018;32(2):396-408.

3. Foran B, Pound R. NBCCA: Complete conditioning for basketball. Champaign, IL: Human Kinetics; 2007.

4. Wen N, Dalbo VJ, Burgos B, Pyne DB, Scanlan AT. Power testing in basketball: Current practice and future recommendations. J Strength Cond Res 2018;32(9):2677-91. 
5. Mcgee KJ, Burkett LN. The National Football League combine: a reliable predictor of draft status? J Strength Cond Res 2003;17(1):6-11.

6. Kuzmits FE, Adams AJ. The NFL combine: does it predict performance in the National Football League? J Strength Cond Res 2008;22(6):1721-7.

7. Robbins DW. The National Football League (NFL) combine: does normalized data better predict performance in the NFL draft? J Strength Cond Res 2010;24(11):2888-99.

8. Team SD. Stan: A C++ Library for Probability and Sampling; 2015. Avaliable from: https://mc-stan.org/ [2018 jun 23].

9. McElreath R. Rethinking: an R package for fitting and manipulating Bayesian models. Version 1.56; 2016. Avaliable from: http://xcelab.net/R/rethinking_package.pdf [2018 jun 23].

10. McElreath R. Statistical rethinking: a Bayesian course with examples in $\mathrm{R}$ and Stan. Boca Raton, FL: Chapman \& Hall/CRC Press; 2015.

11. Team RC. R: A Language and Environment for Statistical Computing. Vienna, Austria: R Foundation for Statistical Computing; 2015.

12. Berri DJ, Brook SL, Fenn AJ. From college to the pros: Predicting the NBA amateur player draft. J Prod Analysis 2011;35(1):25-35.

13. Rodenberg RM, Woo Kim J. Precocity and labor market outcomes: evidence from professional basketball. Econ Bull 2011;31(3):2185-90.

14. Moxley JH, Towne TJ. Predicting success in the national basketball association: Stability \& potential. Psychol Sport Exerc 2015;16(1):128-36.

15. Hoffman JR, Tenenbaum G, Maresh CM, Kraemer WJ. Relationship between athletic performance tests and playing time in elite college basketball players. J Strength Cond 1996;10(2):67-71.

16. Lowe Z. Grantland: a whole new ballgame; 2012. Available from: http://grantland. com/features/what-next-trend-sweep-nba/ [2018 jul 03].

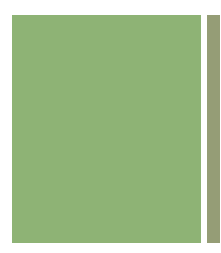

Corresponding author

Fabrício João Milan

Department Physical Education, Sports Center,

Federal University of Santa Catarina

Campus Reitor João David Ferreira Lima, 88040-900 Florianópolis

Florianópolis/Santa Catarina, Brazil

E-mail: fabriciojmilan@gmail.com 